Original scientific paper

\title{
MODELLING OF MICRO-TURNING PROCESS BASED ON CONSTANT CUTTING FORCE
}

\author{
Vukelic, D.*; Kanovic, Z. ; Sokac, M.*; Santosi, Z.*; Budak, I.* \& Tadic, B. ${ }^{* *}$ \\ *University of Novi Sad, Faculty of Technical Sciences, Trg Dositeja Obradovica 6, 21000 Novi Sad, \\ Serbia \\ ${ }^{* *}$ University of Kragujevac, Faculty of Engineering, Sestre Janjic 6, 34000 Kragujevac, Serbia \\ E-Mail: vukelic@uns.ac.rs
}

\begin{abstract}
In this research, an evaluation of the external transverse micro-turning with conventional cutting inserts was performed with a constant cutting force in a dry environment. During machining, the number of revolutions, machining time and cutting forces was varied. Before and after machining, the diameter of the workpiece, circularity and the roughness of the machined surface was measured. The obtained results indicate that with increasing number of revolutions, time and cutting force, the cutting depth increases. The results show that this type of machining can achieve very small cutting depths and reduce circularity deviation and roughness of the machined surface. Based on the experimental results, the modelling of the artificial neural network (ANN) was performed which reliably predicted the change in diameter, cylindricity, and roughness after micro-turning operation, with a mean percentage error smaller than $3 \%$. It can be concluded that the application of ANN is adequate during the machining process with the constant cutting force, since the output parameters can be predicted with small error, while also reducing effort and costs.

(Received in December 2020, accepted in January 2021. This paper was with the authors 1 week for 1 revision.)
\end{abstract}

Key Words: Micro-Turning, Constant Cutting Force, Artificial Neural Network, Cutting Quality

\section{INTRODUCTION}

In recent years, the demand for microcomponents in various industries has become more pronounced. For the production of microcomponents, the most commonly used are electrochemical machining [1], electro discharge machining [2], ion beam machining [3] and laser machining [4]. These methods are characterized by high cost, low productivity and impossibility of application to a wide range of workpiece materials. This has contributed to more and more attention being paid to the research of micro-mechanical machining, i.e., microturning, micro-drilling, micro-milling, etc. [5]. Micro-turning is similar to conventional turning [6], except that the technological equipment is much smaller. Micro-turning is performed on accurate and precise machine tools, most often with diamond cutting tools. High dynamic stiffness is required from the cutting tool to minimize tool wear and tool damage. Manufacturing process can be accompanied by some other undesirable phenomena: low stiffness of the micro tools, unpredictable tool life, poor surface quality, etc. [5].

Conventional turning is performed with a defined cutting depth [7]. One of the problems of this machining method is the difference that inevitably occurs between the defined and the achieved cutting depth [8]. The most common errors are geometric errors, kinematic errors, errors induced by thermal distortions, errors caused by cutting forces, material instability errors, tool wear error, fixturing errors, etc. [9]. Given the dynamics of the cutting process, it is very difficult to establish absolute control over a machining system composed of hundreds of elements. Dimensional deviations and deviations from the geometrical specifications of the product must be achieved within the allowed tolerance limits. One way to minimize deviations is to predict and compensate for systematic and random errors that will occur during the machining process [10]. However, the complexity of the machining system requires the monitoring and control of a large number of influential quantities, so the prediction model 
cannot completely eliminate errors [11]. The big problem is the lack of a universal prediction model. Today, there are several solutions in the form of mathematical models of prediction [12]. Accordingly, the authors in [13] created a mathematical model for better prediction of the micro-turning process and the turning behaviour such as the real feed rate, real cutting depth and the cutting and feed forces. In addition, in the field of micro-machining, machining parameters [14], surface roughness [15], vibration cutting [16] and surface integrity [17] using micro tools were analysed. Effects of the friction coefficient in micro-cutting were also investigated in [18].

The problem of achieving a given cutting depth has initiated research based on a completely different principle of machining. These studies are based on machining with a constant cutting force $[19,20]$. A constant cutting force is given to the cutting tool instead of the cutting depth. A useful method for increasing the material removal rate $(M R R)$ and the tool life of turning systems is by controlling a constant cutting force [21]. Maintaining a constant cutting force is realized with the use of artificial intelligence or fuzzy controllers. It is shown that the adaptive control constraint system based on the fuzzy linguistic rules can achieve an automatic on-line adjustment of feed rate to optimize the production rate even under the variation of cutting conditions in turning [22]. Constant $M R R$ with constant cutting force $(C C F)$ that operates by a fuzzy controller able to automatically manipulate the spindle speed to maintain the $M R R$ at a specified suitable value is examined in [23]. The $C C F$ in turning process under various cutting conditions can also be controlled with a grey-fuzzy control scheme [24, 25]. A simulation study of a $C C F$ in turning process indicated that careful design and use of a fixed-gain sliding mode controller with output feedback can give a roughly equivalent performance to that of more complex adaptive controllers [26].

The previously mentioned research papers deal with the study of the turning process with the control of the cutting force, on which the cutting depth depends, i.e., workpiece dimension. The performed experimental research studied the process of micro-turning on micro workpieces. However, the need for high dimensional accuracy and surface quality of machined macro workpieces requires the study of the process of micro-turning but applied to macro workpieces. Previous research in the field of micro-turning is characterized by the use of micro tools. The micro tools presented in previous research belong to special cutting tools and do not have a possibility of their universal application. Furthermore, the production of micro tools is complicated and expensive. Their stiffness is lower, they are easily worn out and broken. This significantly limits the possibility of their application.

Unlike the previous ones, in this research the possibility of micro-turning is studied, not with micro tools, but with universal tools. The basic hypothesis of this research is that it is possible to perform the process of micro-turning with universal cutting tools, by defining the cutting force and not the cutting depth. The method is based on a constant cutting force. The aim of experimental research is to examine the possibility of micro-turning and to assess the impact of machining parameters on the dimensions, circularity and roughness. Furthermore, an additional goal is to develop a model of ANN for prediction of input machining parameters and to evaluate the performance of ANN model for prediction of output parameters.

\section{METHODOLOGY}

Fig. 1 shows the methodology applied in the research. The research was conducted on workpieces made of steel AISI 1045 whose chemical composition is: (98.51-98.98) \% Fe, $(0.60-0.90) \% \mathrm{Mn},(0.42-0.5) \% \mathrm{C}$, less than $0.05 \% \mathrm{~S}$ and less than $0.04 \% \mathrm{P}$. The mechanical and physical characteristics of steel AISI 1045 are: density $=7.87 \mathrm{~g} / \mathrm{cm}^{3}$, hardness $=163 \mathrm{HB}$, tensile strength $=565 \mathrm{MPa}$, yield strength $=310 \mathrm{MPa}$, modulus of elasticity $=200 \mathrm{GPa}$ and Poisson ratio $=0.29$. 


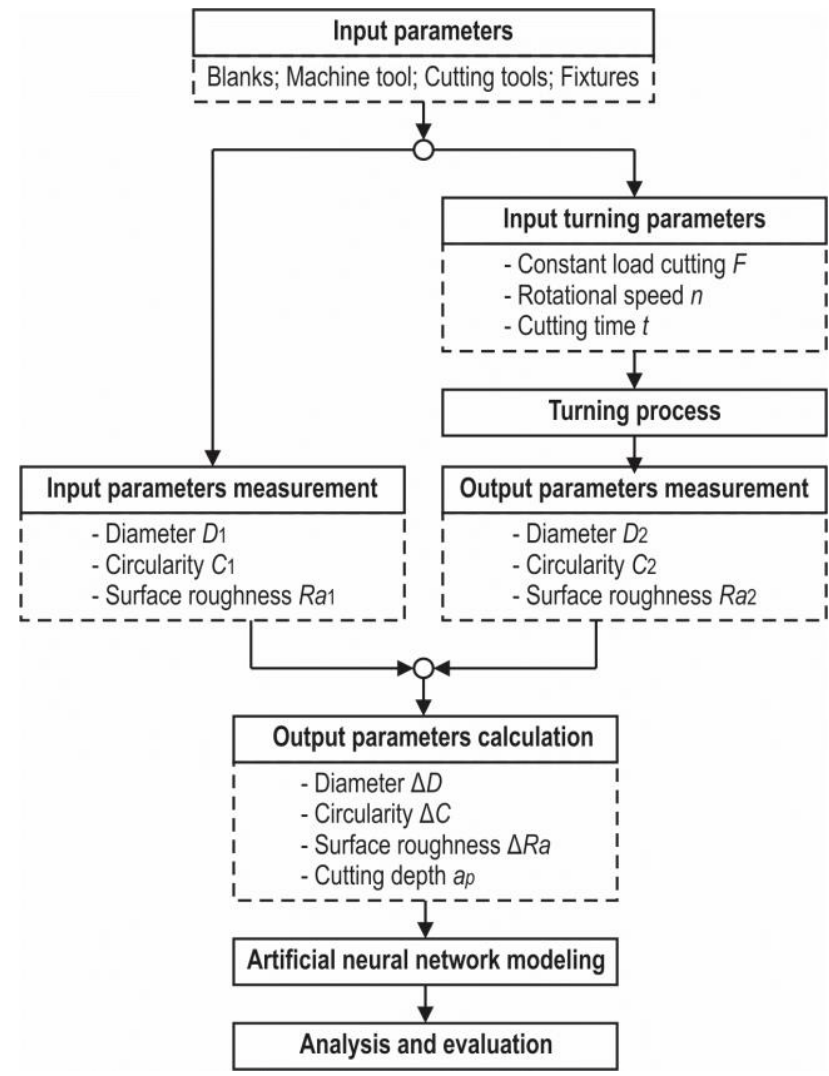

Figure 1: Methodology.

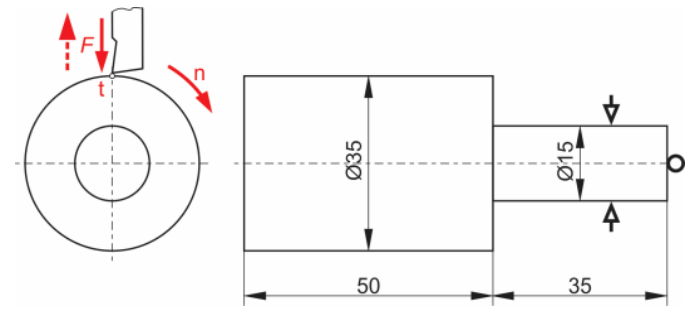

Figure 2: Turning principle.

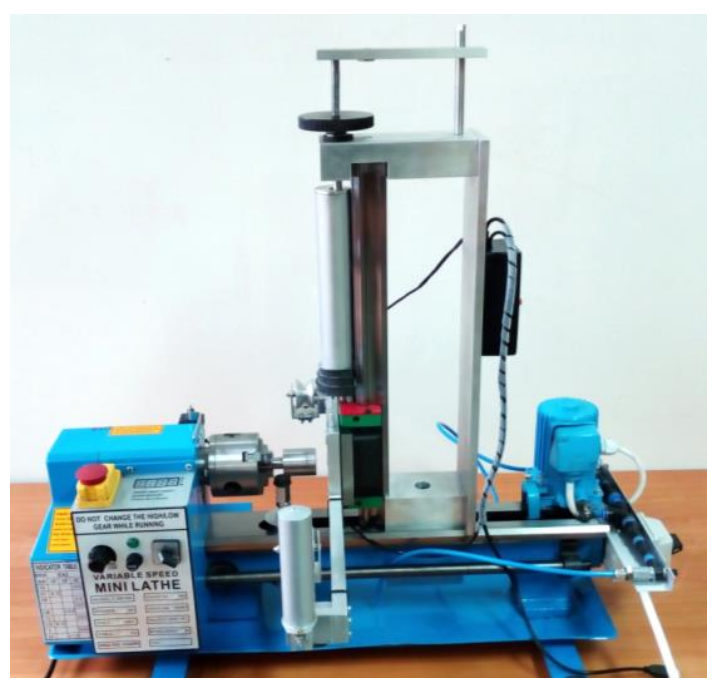

Figure 3: Photoimage of experimental research.

In order to obtain identical initial conditions, workpieces were prepared. It involved scraping and grinding workpieces to the initial dimensions and the initial mean arithmetic roughness of $R a=0.8 \mu \mathrm{m}$ (Fig. 2).

Turning is performed on a universal mini lathe (model: CJ0618/A/BX350), which was upgraded for the purpose of performing the experiment with a module for setting a constant cutting force (Fig. 3). The cutting tool with which the machining is performed is made of highspeed steel with a rake angle of $5^{\circ}$ and a flank angle of $5^{\circ}$. Locating and clamping of the workpiece (Fig. 2) was performed using chuck over a cylindrical surface with a diameter of $\varnothing 15 \mathrm{~mm}$ at the length of $35 \mathrm{~mm}$. Transverse turning is performed on a cylindrical surface with a diameter of $\varnothing 35 \mathrm{~mm}$. During machining, it is not the cutting depth that is set but the cutting force via the constant cutting force setting module. The workpiece is placed in the clamping head, and the main auxiliary movement is switched on by setting the number of revolutions $(n)$. Auxiliary rectilinear movement is performed by a cutting tool. The cutting tool is brought into contact with the workpiece via a module for setting a constant cutting force, performing transverse machining. Machining, i.e. the contact between the cutting tool and the workpiece is performed for a pre-defined time $(t)$ after which the tool moves away from the workpiece. During the experimental research, the cutting force, number of revolutions and machining time were varied. For experimental research, the following levels of input values were adopted:

- six levels of cutting force $F=1-2-3-4-5-6(\mathrm{~N})$,

- three levels of number of revolutions $n=50-100-150$ (rev/min),

- three levels of machining time $t=10-15-20$ (s).

Experimental investigations were conducted in accordance with a full factorial experiment that allows the investigation of all levels of input values to the output values of the process. Since 6 levels for force, 3 levels for number of revolutions and 3 levels for machining time were adopted, a total of $6 \times 3 \times 3=54$ experiments were performed. 
Before and after machining, the diameter of the workpiece, the circularity of the workpiece and the arithmetic mean roughness of the machined surface were measured (Fig. 4). Diameter and circularity measurements, before and after machining, were performed on a Contura G2 coordinate measuring machine by Carl Zeiss. To minimize the maximum permissible error, the point-by-point sampling mode is used. The diameter of the measuring stylus was $5 \mathrm{~mm}$. The largest available diameter of the measuring stylus was chosen to reduce the influence of roughness and waviness on the diameter measurement error. Roughness measurement was also performed before and after machining on a Talysurf measuring device with a probe type radius $r=2 \mu \mathrm{m}$. All measurements were performed under controlled microclimatic conditions.

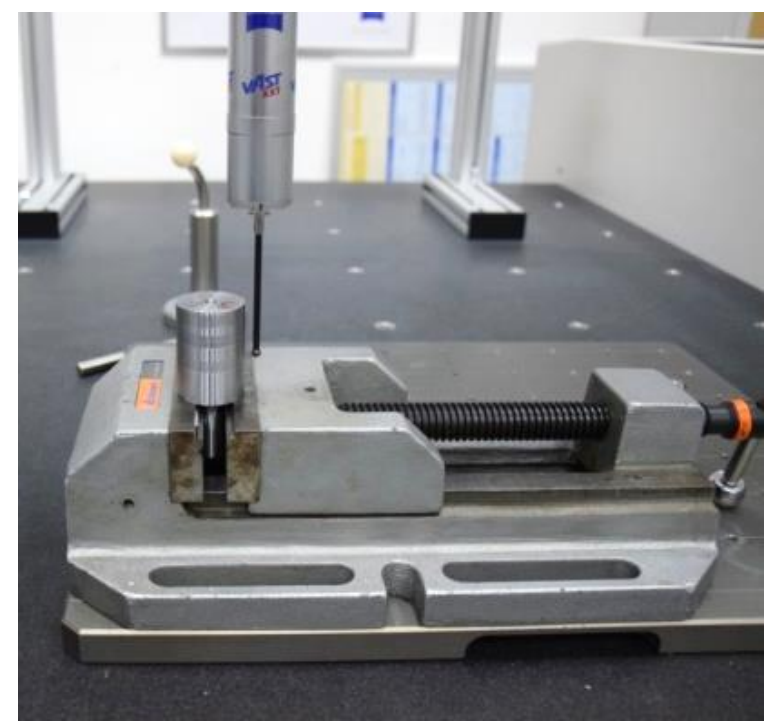

a)

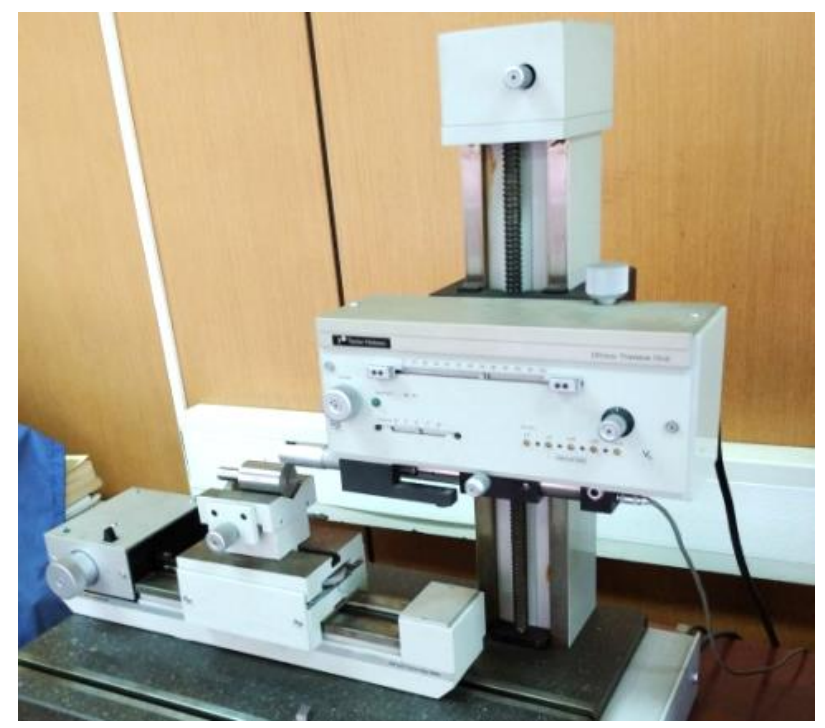

b)

Figure 4: Measurement process, a) diameter and circularity, b) roughness.

Machining parameters depend on a large number of factors. Soft computing techniques (ANN, SVM, etc.) can be very useful for reducing the required time and effort when there are no recommendations and experiential data for the selection of machining parameters when there is no procedure of mathematical interpretation of the machining process, or it is necessary to conduct a large number of experiments. ANN, after proper training and testing, can successfully predict unknown machining parameters. The input data in ANN are force $(F)$, number of revolutions $(n)$ and machining time $(t)$. The output data from ANN are the change of the workpiece diameter $(\Delta D)$, the change of the workpiece circularity $(\Delta C)$ and the change of the arithmetic mean roughness of the machined surface $(\Delta R a)$. The input data are grouped as a whole. The output data are not grouped, ie. a network is created for each output individually.

After the ANN is trained, tested, and verified, confirmed experiments are performed. Quantitative assessment of the possibility of predicting output results using ANN is performed based on percentage error $(P E)$ and mean percentage error $(M P E)$, according to the equations:

$$
\begin{gathered}
P E=\left|\frac{x_{i p v}-x_{i m v}}{x_{i m v}}\right| \cdot 100 \% \\
M P E=\frac{100 \%}{n} \sum_{i=1}^{n}\left|\frac{x_{i p v}-x_{i m v}}{x_{i m v}}\right|
\end{gathered}
$$

where: $x_{i p v}$ - predicted value, $x_{i m v}$ - measured value. Based on the obtained results and errors, the evaluation of assessments and evaluation of the possibility of application is performed, i.e., adequacy of ANN application for prediction of machining output parameters. 


\section{RESULTS}

\subsection{Experimental research}

Table I shows the results of measurements and calculations. The experiments were performed by the run order and the table shows the results in accordance with the standard order for easier monitoring of the obtained results.

Before and after machining, the workpiece diameter $\left(D_{1}, D_{2}\right)$, the workpiece circularity $\left(C_{1}\right.$, $\left.C_{2}\right)$ and the arithmetic mean roughness $\left(R a_{1}, R a_{2}\right)$ were measured. The change in diameter $(\Delta D)$, change in circularity $(\Delta C)$, change in roughness $(\Delta R a)$ and cutting depth $\left(a_{p}\right)$ were calculated using the following equations:

$$
\Delta D=D_{1}-D_{2}, \quad \Delta C=C_{1}-C_{2}, \quad \Delta R a=R a_{1}-R a_{2}, \quad a_{p}=\left(D_{1}-D_{2}\right) / 2=\Delta D / 2
$$

A positive symbol in front of a change in circularity $(\Delta C)$ and a change in roughness $(\Delta R)$ indicates that there has been an improvement in circularity and roughness, and a negative symbol that there has been a deterioration.

Graphical interpretation of the measured results is shown in Fig. 5 and the calculated results are shown in Fig. 6.

Based on the obtained results (Table I, Figs. 5 and 6), the following can be stated:

- At smaller values of cutting force, number of revolutions and machining time, smaller cutting depths and smaller change of diameter are achieved. At low cutting forces $(F=1 \mathrm{~N})$ and low number of revolutions $(n=50 \mathrm{rev} / \mathrm{min})$, regardless of the processing time $(t \leq 20 \mathrm{~s})$, the achieved cutting depth is less than $\left(a_{p}<1 \mu \mathrm{m}\right)$. With the increase of cutting force, number of revolutions and machining time, the change of diameter increases, i.e. cutting depth. This change has a practically constant upward trend to a force of $4 \mathrm{~N}$ (36th experiment). After this force, i.e. at forces of 5 and $6 \mathrm{~N}$ there is a significant increase in the cutting depth and thus a change in diameter, regardless of the number of revolutions and machining time.

- At smaller values of cutting force, regardless of the number of revolutions and machining time, a positive effect on the change of circularity is noticeable. The circularity is improved until experiment no. 13. At processing parameters of $F=2 \mathrm{~N}, n=100 \mathrm{rev} / \mathrm{min}$ and $t=10 \mathrm{~s}$, the greatest improvement of circularity is achieved. After this experiment, the circularity declines, but still, only until experiment no. $26(F=3 \mathrm{~N}, n=150 \mathrm{rev} / \mathrm{min}, t=15 \mathrm{~s})$ the circularity after machining is still better than the initial circularity. After this experiment, even at forces of 4, 5 and $6 \mathrm{~N}$, there is a significant deterioration of the achieved circularity compared to the initial one.

- At smaller values of cutting force, regardless of the number of revolutions and machining time, a positive effect on the change of arithmetic mean roughness is noticeable. Roughness is improved until experiment no. 13. With processing parameters of $F=2 \mathrm{~N}, n=100 \mathrm{rev} / \mathrm{min}$ and $t=10 \mathrm{~s}$, the biggest improvement in roughness is achieved. After this experiment, the roughness declines, but still, until experiment no. $26(F=3 \mathrm{~N}, n=150 \mathrm{rev} / \mathrm{min}, t=15 \mathrm{~s})$ the roughness after machining is still better than the initial roughness $\left(R a_{2}<R a_{1}\right)$. After this experiment and up until experiment no. 36, the achieved roughness is worse than the initial one $\left(R a_{2}>R a_{1}\right)$ and this is a slight deterioration trend. After experiment no. 36, in all experiments where the force is 5 or $6 \mathrm{~N}$, there is a significant deterioration of the arithmetic mean roughness $\left(R a_{2} \gg>a_{1}\right)$. Roughness declines with greater cutting force, number of revolutions and machining time. 
Vukelic, Kanovic, Sokac, Santosi, Budak, Tadic: Modelling of Micro-Turning Process Based ...

Table I: Experimental results.

\begin{tabular}{|c|c|c|c|c|c|c|c|c|c|c|c|c|c|c|}
\hline Std & Run & $\begin{array}{c}F \\
(\mathrm{~N})\end{array}$ & $\begin{array}{c}n \\
(\mathrm{rev} / \mathrm{min})\end{array}$ & $\begin{array}{c}t \\
(\mathrm{~s})\end{array}$ & $\begin{array}{c}D_{1} \\
(\mathrm{~mm})\end{array}$ & $\begin{array}{c}D_{2} \\
(\mathrm{~mm})\end{array}$ & $\begin{array}{c}\Delta D \\
(\mathrm{~mm})\end{array}$ & $\begin{array}{c}C_{1} \\
(\mathrm{~mm})\end{array}$ & $\begin{array}{c}C_{2} \\
(\mathrm{~mm})\end{array}$ & $\begin{array}{c}\Delta C \\
(\mathrm{~mm})\end{array}$ & $\begin{array}{l}R a_{1} \\
(\mu \mathrm{m})\end{array}$ & $\begin{array}{l}R a_{2} \\
(\mu \mathrm{m})\end{array}$ & $\begin{array}{c}\Delta R \\
(\mu \mathrm{m})\end{array}$ & $\begin{array}{c}a_{p} \\
(\mu \mathrm{m})\end{array}$ \\
\hline 1 & 41 & 1 & 50 & 10 & 35.0972 & 35.0961 & 0.0011 & 0.0354 & 0.0208 & 0.0146 & 0.802 & 0.516 & 0.286 & 0.55 \\
\hline 2 & 9 & 1 & 50 & 15 & 35.0983 & 35.0970 & 0.0013 & 0.0355 & 0.0209 & 0.0146 & 0.805 & 0.519 & 0.286 & 0.65 \\
\hline 3 & 7 & 1 & 50 & 20 & 35.0922 & 35.0907 & 0.0015 & 0.0369 & 0.0223 & 0.0146 & 0.812 & 0.498 & 0.314 & 0.75 \\
\hline 4 & 53 & 1 & 100 & 10 & 35.1145 & 35.1125 & 0.0020 & 0.0372 & 0.0225 & 0.0147 & 0.806 & 0.492 & 0.314 & 1.00 \\
\hline 5 & 54 & 1 & 100 & 15 & 35.1135 & 35.1113 & 0.0022 & 0.0367 & 0.0218 & 0.0149 & 0.785 & 0.471 & 0.314 & 1.10 \\
\hline 6 & 29 & 1 & 100 & 20 & 35.1107 & 35.1083 & 0.0024 & 0.0367 & 0.0218 & 0.0149 & 0.794 & 0.451 & 0.343 & 1.20 \\
\hline 7 & 45 & 1 & 150 & 10 & 35.0778 & 35.0750 & 0.0028 & 0.0384 & 0.0233 & 0.0151 & 0.801 & 0.430 & 0.371 & 1.40 \\
\hline 8 & 13 & 1 & 150 & 15 & 35.0801 & 35.0770 & 0.0031 & 0.0404 & 0.0250 & 0.0154 & 0.811 & 0.382 & 0.429 & 1.55 \\
\hline 9 & 11 & 1 & 150 & 20 & 35.0795 & 35.0761 & 0.0034 & 0.0398 & 0.0242 & 0.0156 & 0.805 & 0.348 & 0.457 & 1.70 \\
\hline 10 & 16 & 2 & 50 & 10 & 35.0979 & 35.0944 & 0.0035 & 0.0374 & 0.0207 & 0.0167 & 0.802 & 0.116 & 0.686 & 1.75 \\
\hline 11 & 15 & 2 & 50 & 15 & 35.08 & 35.0795 & 0.0037 & 0.0372 & & 0.0168 & 0.802 & 0.059 & 0.743 & 1.85 \\
\hline 12 & 10 & 2 & 50 & 20 & 35.1073 & 35.1034 & 0.0039 & 0.0375 & 0.0206 & 0.0169 & 0.804 & 0.025 & 0.779 & .95 \\
\hline 13 & 18 & 2 & 100 & 10 & 35.1223 & 35.1180 & 0.0043 & 0.0392 & 0.0220 & 0.0172 & 0.809 & 0.020 & 0.789 & 2.15 \\
\hline 14 & 30 & 2 & 100 & 15 & 35.08 & 35.0764 & & 0.0397 & & 0.0144 & 0.808 & 0.049 & 0.759 & 35 \\
\hline 15 & 34 & 2 & 100 & 20 & 35.06 & 35.0572 & 0.0049 & 0.0387 & 0.0246 & 0.0141 & 0.810 & .133 & 0.677 & 2.45 \\
\hline 16 & 20 & 2 & 150 & 10 & 35.1156 & 35.1100 & 0.0056 & 0.0374 & 0.0235 & 0.0139 & 0.804 & 0.139 & 0.665 & 2.80 \\
\hline 17 & 37 & 2 & 150 & 15 & 35.0 & 35.0619 & 0.0059 & 0.0383 & 0.0245 & 0.0138 & 0.805 & 0.195 & 0.610 & 2.95 \\
\hline 18 & 40 & 2 & & 20 & 35.04 & 35.0361 & & 0.0371 & & 0.0137 & 0.809 & .248 & .561 & 3.10 \\
\hline 19 & 23 & 3 & 50 & 10 & 35.0811 & 35.0746 & 0.0065 & 0.0313 & 0.0220 & 0.0093 & 0.795 & 0.519 & 0.276 & 3.25 \\
\hline 20 & 21 & 3 & 50 & 15 & 35.0957 & 35.0890 & 0.0067 & 0.0330 & 0.0251 & 0.0079 & 0.806 & 0.537 & 0.269 & 3.35 \\
\hline 21 & 46 & 3 & 50 & 20 & 35.10 & 35.1003 & 0.0071 & 0.0319 & & 0.0059 & 0.807 & .593 & .214 & 3.55 \\
\hline 22 & 32 & 3 & 100 & 10 & 35.0879 & 35.0806 & 0.0073 & 0.0394 & 0.0346 & 0.0048 & 0.789 & 0.611 & 0.178 & 3.65 \\
\hline 23 & 6 & 3 & 100 & 15 & 35.0 & 35.08 & & 0.0385 & & 0.0039 & 0.793 & 0.636 & .157 & 95 \\
\hline 24 & & 3 & & 20 & 35.0 & 35.0 & & 0.0391 & & 0.0035 & 0.802 & .684 & .118 & 25 \\
\hline 25 & 26 & 3 & 150 & 10 & 35.1045 & 35.0955 & 0.0090 & 0.0411 & 0.0387 & 0.0024 & 0.796 & 0.718 & 0.078 & 4.50 \\
\hline 26 & 44 & 3 & 15 & 15 & 35.0 & 35.0362 & & 0.0418 & & 0.0015 & 0.805 & 0.786 & 0.019 & 4.70 \\
\hline 27 & 17 & 3 & & 20 & 35.0 & 35.0460 & 0.0099 & 0.0419 & 0.0434 & -0.0015 & 0.793 & 0.807 & -0.014 & 4.95 \\
\hline 28 & 1 & 4 & 50 & 10 & 35.0467 & 35.0356 & 0.0111 & 0.0405 & 0.0440 & -0.0035 & 0.807 & 1.107 & -0.300 & 5.55 \\
\hline 29 & 2 & 4 & 5 & 15 & 35.0943 & 35.0829 & & 0.0402 & 0.0438 & -0.0036 & 0.809 & 1.162 & -0.353 & 5.70 \\
\hline 30 & 24 & 4 & 50 & 20 & 35.10 & 35.0882 & 0.0121 & 0.0411 & 0.0448 & -0.0037 & 0.809 & 1.220 & -0.411 & 6.05 \\
\hline 31 & 5 & 4 & 100 & 10 & 35.0571 & 35.0447 & 0.0124 & 0.0423 & 0.0462 & -0.0039 & 0.805 & 1.224 & -0.419 & 6.20 \\
\hline 32 & 27 & 4 & 100 & 15 & 35.1171 & 35.1037 & & 0.0421 & & -0.0042 & 0.806 & 1.251 & -0.445 & 70 \\
\hline 33 & 31 & 4 & 100 & 20 & 35.0529 & 35.0384 & 0.0145 & 0.0422 & 0.0467 & -0.0045 & 0.802 & 1.312 & -0.510 & 7.25 \\
\hline 34 & 19 & 4 & 150 & 10 & 35.1116 & 35.0964 & 0.0152 & 0.0426 & 0.0477 & -0.0051 & 0.804 & 1.339 & -0.535 & 7.60 \\
\hline 35 & 47 & 4 & & 15 & 35.0 & & & 0.0429 & & & & 1.417 & -0.605 & \\
\hline 36 & 43 & 4 & 150 & 20 & 35.0443 & 35.0274 & 0.0169 & 0.0431 & 0.0491 & -0.006 & 0.802 & 1.512 & -0.710 & 8.45 \\
\hline 37 & 22 & 5 & 50 & 10 & 35.0611 & 35.0246 & 0.0365 & 0.0323 & 0.0425 & -0.0102 & 0.802 & 4.941 & -4.139 & 18.25 \\
\hline 38 & 52 & 5 & & 15 & 35.02 & 34.9855 & & 0.0331 & & & 08 & 6.535 & -5.727 & 8.80 \\
\hline 39 & & 5 & 50 & 20 & 35.0562 & 35.0164 & 0.0398 & 0.0330 & 0.0444 & -0.0114 & 0.802 & 8.427 & -7.625 & 19.90 \\
\hline 40 & 51 & 5 & 100 & 10 & 35.0967 & 35.0557 & 0.0410 & 0.0352 & 0.0471 & -0.0119 & 0.805 & 8.966 & -8.161 & 20.50 \\
\hline 41 & 3 & 5 & & 15 & 35.0 & 35.0235 & & 0.0349 & & & 0.8 & 0.143 & -9.337 & 2.15 \\
\hline 42 & 33 & 5 & 100 & 20 & 35.0911 & 35.0434 & 0.0477 & 0.0356 & 0.0482 & -0.0126 & 0.812 & 12.045 & -11.233 & 23.85 \\
\hline 43 & 36 & 5 & & 10 & 35.0856 & 35.0353 & 0.0503 & 0.0355 & 0.0486 & -0.0131 & 0.811 & 12.218 & -11.407 & 25.15 \\
\hline 44 & 28 & 5 & & 15 & 35.0441 & 34.9911 & 0.0530 & 0.0352 & 0.0484 & -0.0132 & 0.811 & 14.135 & -13.324 & 26.50 \\
\hline 45 & 8 & 5 & 150 & 20 & 35.0456 & 34.9899 & 0.0557 & 0.0352 & 0.0490 & -0.0138 & 0.802 & 15.827 & -15.025 & 27.85 \\
\hline 46 & 39 & 6 & 50 & 10 & 35.0321 & 34.9722 & 0.0599 & 0.0389 & 0.0543 & -0.0154 & 0.805 & 17.783 & -16.978 & 29.95 \\
\hline 47 & 49 & 6 & 5 & 15 & 35.02 & 34.9678 & & & & & 0.8 & & .335 & 31.05 \\
\hline 48 & 42 & 6 & 50 & 20 & 35.0152 & 34.9471 & 0.0681 & 0.0388 & 0.0555 & -0.0167 & 0.809 & 18.809 & -18.000 & 34.05 \\
\hline 49 & 14 & 6 & 100 & 10 & 35.0519 & 34.9790 & 0.0729 & 0.0362 & 0.0545 & -0.0183 & 0.801 & 19.258 & -18.457 & 36.45 \\
\hline 50 & 48 & 6 & & 15 & & & & & & & & & & 37.85 \\
\hline 51 & 3 & 6 & 100 & 20 & 35.0822 & 35.0038 & 0.0784 & 0.0381 & 0.0577 & -0.0196 & 0.809 & 19.876 & -19.067 & 39.20 \\
\hline 52 & 38 & 6 & 150 & 10 & 35.0245 & 34.9433 & 0.0812 & 0.0371 & 0.0573 & -0.0202 & 0.804 & 20.838 & -20.034 & 40.60 \\
\hline 53 & 25 & 6 & 150 & 15 & 35.0427 & 34.9586 & 0.0841 & 0.0372 & 0.0589 & -0.0217 & 0.808 & 21.829 & -21.021 & 42.05 \\
\hline 54 & 12 & 6 & 150 & 20 & 35.0265 & 34.9406 & 0.0859 & 0.0381 & 0.0605 & -0.0224 & 0.803 & 23.124 & -22.321 & 42.95 \\
\hline \multicolumn{5}{|c|}{ Mean } & 35.0739 & 35.0493 & 0.0247 & 0.0378 & 0.0380 & -0.0002 & 0.804 & 5.467 & -4.663 & 12.33 \\
\hline \multicolumn{5}{|c|}{ Minimum } & 35.0152 & 34.9406 & 0.0011 & 0.0313 & 0.0204 & -0.0224 & 0.785 & 0.020 & -22.321 & 0.55 \\
\hline \multicolumn{5}{|c|}{ Maximum } & 35.1223 & 35.1180 & 0.0859 & 0.0431 & 0.0605 & 0.0172 & 0.812 & 23.124 & 0.789 & 42.95 \\
\hline \multicolumn{5}{|c|}{ Standard Deviation } & 0.0289 & 0.0503 & 0.0270 & 0.0030 & 0.0133 & 0.0131 & 0.006 & 7.618 & 7.617 & 13.51 \\
\hline
\end{tabular}




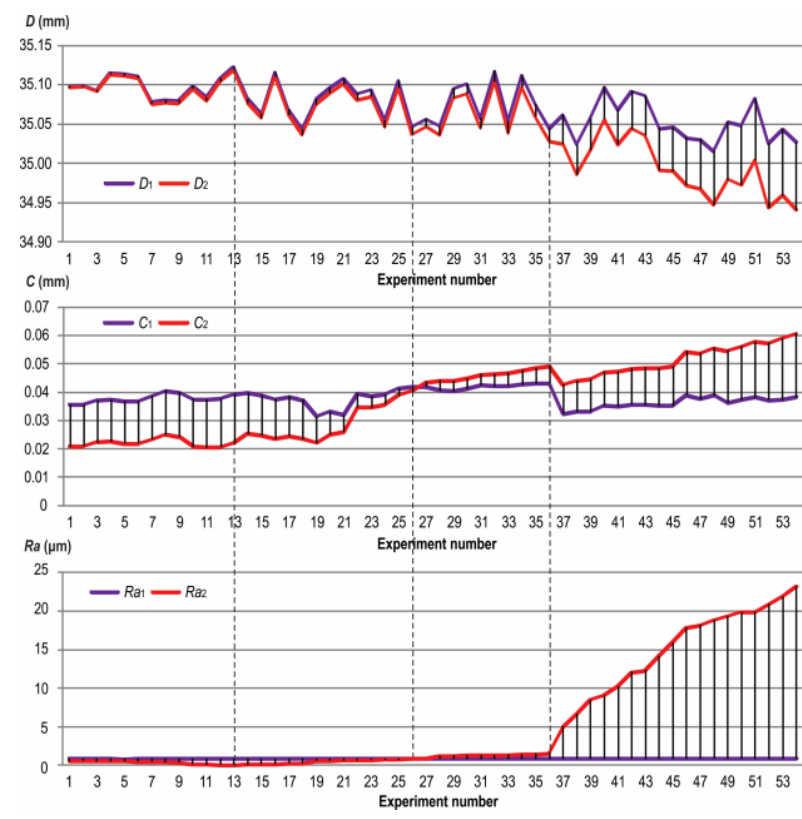

Figure 5: Measured results before and after machining.

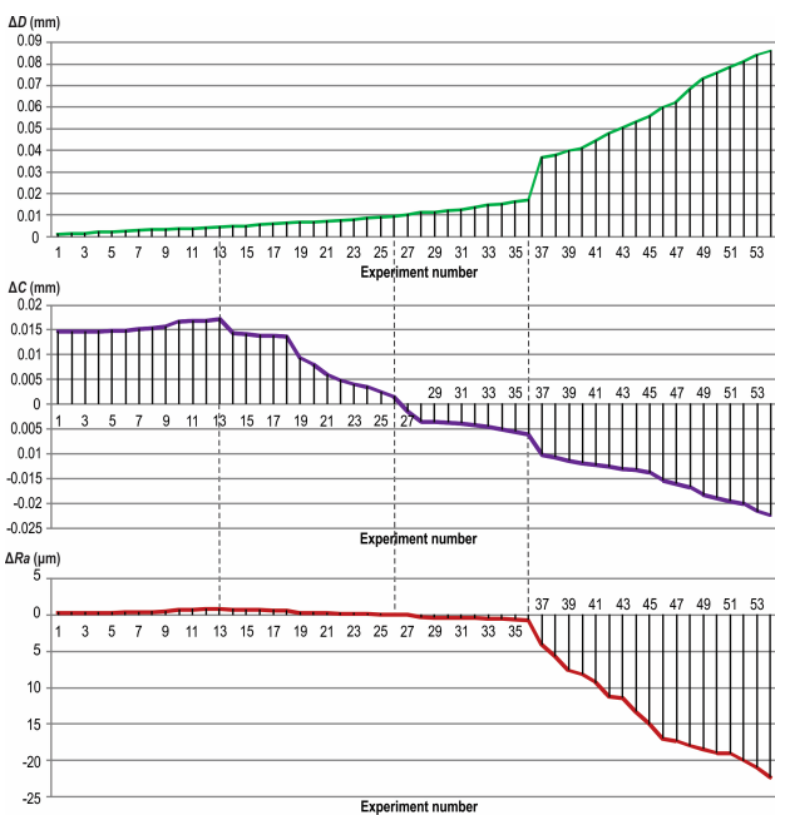

Figure 6: Calculated results after machining.

\subsection{Modelling of the micro-turning process}

After experimental research, the ANN was created. The ANN should predict the output parameters of the machining process based on input parameters. The designed ANN is a threelayer feedforward network, with a sigmoid transfer function in the two hidden layers and a linear transfer function in the output layer. The architecture for hidden layers is 4-3, which has been chosen by investigating multiple different architectures and using the trial-and-error method. Network training has been conducted using the Levenberg-Marquardt backpropagation algorithm. To improve the generalization and avoid overfitting, the early stopping method has been employed. In this technique the available data is randomly divided into three subsets training set ( $70 \%$ of data), validation set ( $15 \%$ of data) and test set (15\% of data). The training set is used for computing the gradient and updating the network weights and biases. The validation set is used to monitor the error during the training process. Usually, both validation error and training error decrease in the initial part of training. Later, if data overfitting occurs, the validation set error starts to rise. From that moment on, after the validation error is increased for a given number of iterations, the training is stopped. The weights and biases computed at the time when the validation error was minimal are returned. The error of the test set is used only to compare different models and has no direct influence to training process. However, it is of interest to monitor the test set error during the training. If the test set error does not reach a minimum at a similar iteration number as the validation set error, this might indicate that division of the data set was not appropriate. The obtained data are shown in Table II. The same table also shows the comparison of experimental and predictive values of diameter change, circularity change and arithmetic mean roughness change, over absolute and percentage error.

\subsection{Confirmation experiments}

Performance evaluation of the generated model, i.e. the accuracy verification of the ANN model was performed on bases of 10 additional experiments. Table III shows the results of measuring the output machining parameters and Table IV shows the prediction of the output machining parameters and the obtained errors (PE, MPE). 
Vukelic, Kanovic, Sokac, Santosi, Budak, Tadic: Modelling of Micro-Turning Process Based ...

Table II: Percentage errors.

\begin{tabular}{|c|c|c|c|c|c|c|c|c|c|c|}
\hline \multirow[b]{2}{*}{$\begin{array}{l}\text { Std } \\
\text { order }\end{array}$} & \multirow[b]{2}{*}{$\begin{array}{l}\text { Run } \\
\text { order }\end{array}$} & \multicolumn{3}{|c|}{$\Delta D(\mathrm{~mm})$} & \multicolumn{3}{|c|}{$\Delta C(\mathrm{~mm})$} & \multicolumn{3}{|c|}{$\Delta R a(\mu \mathrm{m})$} \\
\hline & & $\begin{array}{l}\text { Measured } \\
\text { value }\end{array}$ & $\begin{array}{c}\text { Predicted } \\
\text { value }\end{array}$ & $\begin{array}{l}P E \\
(\%)\end{array}$ & $\begin{array}{l}\text { Measured } \\
\text { value }\end{array}$ & $\begin{array}{c}\text { Predicted } \\
\text { value }\end{array}$ & $\begin{array}{l}P E \\
(\%)\end{array}$ & $\begin{array}{l}\text { Measured } \\
\text { value }\end{array}$ & $\begin{array}{c}\text { Predicted } \\
\text { value }\end{array}$ & $\begin{array}{l}P E \\
(\%)\end{array}$ \\
\hline 1 & 41 & 0.0011 & 0.00113 & 2.73 & 0.0146 & 0.01438 & 1.51 & 0.286 & 0.2935 & 2.62 \\
\hline 2 & 9 & 0.0013 & 0.00132 & 1.54 & 0.0146 & 0.01410 & 3.42 & 0.286 & 0.2921 & 2.13 \\
\hline 3 & 7 & 0.0015 & 0.00153 & 2.00 & 0.0146 & 0.01497 & 2.53 & 0.314 & 0.3094 & 1.46 \\
\hline 4 & 53 & 0.0020 & 0.00206 & 3.00 & 0.0147 & 0.01443 & 1.84 & 0.314 & 0.3181 & 1.31 \\
\hline 5 & 54 & 0.0022 & 0.00217 & 1.36 & 0.0149 & 0.01531 & 2.75 & 0.314 & 0.3257 & 3.73 \\
\hline 6 & 29 & 0.0024 & 0.00236 & 1.67 & 0.0149 & 0.01489 & 0.07 & 0.343 & 0.3550 & 3.50 \\
\hline 7 & 45 & 0.0028 & 0.00287 & 2.50 & 0.0151 & 0.01555 & 2.98 & 0.371 & 0.3673 & 1.00 \\
\hline 8 & 13 & 0.0031 & 0.00316 & 1.94 & 0.0154 & 0.01541 & 0.06 & 0.429 & 0.4463 & 4.03 \\
\hline 9 & 11 & 0.0034 & 0.00337 & 0.88 & 0.0156 & 0.01532 & 1.79 & 0.457 & 0.4635 & 1.42 \\
\hline 10 & 16 & 0.0035 & 0.00341 & 2.57 & 0.0167 & 0.01672 & 0.12 & 0.686 & 0.6966 & 1.55 \\
\hline 11 & 15 & 0.0037 & 0.00361 & 2.43 & 0.0168 & 0.01618 & 3.69 & 0.743 & 0.7574 & 1.94 \\
\hline 12 & 10 & 0.0039 & 0.00395 & 1.28 & 0.0169 & 0.01641 & 2.90 & 0.779 & 0.7650 & 1.80 \\
\hline 13 & 18 & 0.0043 & 0.00435 & 1.16 & 0.0172 & 0.01690 & 1.74 & 0.789 & 0.7649 & 3.05 \\
\hline 14 & 30 & 0.0047 & 0.00467 & 0.64 & 0.0144 & 0.01463 & 1.60 & 0.759 & 0.7360 & 3.03 \\
\hline 15 & 34 & 0.0049 & 0.00500 & 2.04 & 0.0141 & 0.01422 & 0.85 & 0.677 & 0.6466 & 4.49 \\
\hline 16 & 20 & 0.0056 & 0.00561 & 0.18 & 0.0139 & 0.01356 & 2.45 & 0.665 & 0.6361 & 4.35 \\
\hline 17 & 37 & 0.0059 & 0.00589 & 0.17 & 0.0138 & 0.01332 & 3.48 & 0.610 & 0.6300 & 3.28 \\
\hline 18 & 40 & 0.0062 & 0.00617 & 0.48 & 0.0137 & 0.01338 & 2.34 & 0.561 & 0.5874 & 4.71 \\
\hline 19 & 23 & 0.0065 & 0.00641 & 1.38 & 0.0093 & 0.00905 & 2.69 & 0.276 & 0.2634 & 4.57 \\
\hline 20 & 21 & 0.0067 & 0.00679 & 1.34 & 0.0079 & 0.00759 & 3.92 & 0.269 & 0.2589 & 3.75 \\
\hline 21 & 46 & 0.0071 & 0.00717 & 0.99 & 0.0059 & 0.00604 & 2.37 & 0.214 & 0.2165 & 1.17 \\
\hline 22 & 32 & 0.0073 & 0.00752 & 3.01 & 0.0048 & 0.00483 & 0.63 & 0.178 & 0.1850 & 3.93 \\
\hline 23 & 6 & 0.0079 & 0.00799 & 1.14 & 0.0039 & 0.00378 & 3.08 & 0.157 & 0.1628 & 3.69 \\
\hline 24 & 50 & 0.0085 & 0.00841 & 1.06 & 0.0035 & 0.00358 & 2.29 & 0.118 & 0.1214 & 2.88 \\
\hline 25 & 26 & 0.0090 & 0.00908 & 0.89 & 0.0024 & 0.00245 & 2.08 & 0.078 & 0.0746 & 4.36 \\
\hline 26 & 44 & 0.0094 & 0.00933 & 0.74 & 0.0015 & 0.00147 & 2.00 & 0.019 & 0.0193 & 1.58 \\
\hline 27 & 17 & 0.0099 & 0.00959 & 3.13 & -0.0015 & -0.00153 & 2.00 & -0.014 & -0.0137 & 2.14 \\
\hline 28 & 1 & 0.0111 & 0.01080 & 2.70 & -0.0035 & -0.00338 & 3.43 & -0.300 & -0.3106 & 3.53 \\
\hline 29 & 2 & 0.0114 & 0.01142 & 0.18 & -0.0036 & -0.00348 & 3.33 & -0.353 & -0.3627 & 2.75 \\
\hline 30 & 24 & 0.0121 & 0.01219 & 0.74 & -0.0037 & -0.00376 & 1.62 & -0.411 & -0.4199 & 2.17 \\
\hline 31 & 5 & 0.0124 & 0.01250 & 0.81 & -0.0039 & -0.00403 & 3.33 & -0.419 & -0.3997 & 4.61 \\
\hline 32 & 27 & 0.0134 & 0.01379 & 2.91 & -0.0042 & -0.00432 & 2.86 & -0.445 & -0.4245 & 4.61 \\
\hline 33 & 31 & 0.0145 & 0.01471 & 1.45 & -0.0045 & -0.00466 & 3.56 & -0.510 & -0.5127 & 0.53 \\
\hline 34 & 19 & 0.0152 & 0.01522 & 0.13 & -0.0051 & -0.00530 & 3.92 & -0.535 & -0.5444 & 1.76 \\
\hline 35 & 47 & 0.0160 & 0.01595 & 0.31 & -0.0055 & -0.00564 & 2.55 & -0.605 & -0.6304 & 4.20 \\
\hline 36 & 43 & 0.0169 & 0.01693 & 0.18 & -0.0060 & -0.00602 & 0.33 & -0.710 & -0.7174 & 1.04 \\
\hline 37 & 22 & 0.0365 & 0.03639 & 0.30 & -0.0102 & -0.01029 & 0.88 & -4.139 & -4.1983 & 1.43 \\
\hline 38 & 52 & 0.0376 & 0.03844 & 2.23 & -0.0107 & -0.01078 & 0.75 & -5.727 & -5.6284 & 1.72 \\
\hline 39 & 4 & 0.0398 & 0.03969 & 0.28 & -0.0114 & -0.01130 & 0.88 & -7.625 & -7.5273 & 1.28 \\
\hline 40 & 51 & 0.0410 & 0.03988 & 2.73 & -0.0119 & -0.01168 & 1.85 & -8.161 & -8.3578 & 2.41 \\
\hline 41 & 35 & 0.0443 & 0.04329 & 2.28 & -0.0123 & -0.01217 & 1.06 & -9.337 & -9.1167 & 2.36 \\
\hline 42 & 33 & 0.0477 & 0.04919 & 3.12 & -0.0126 & -0.01268 & 0.63 & -11.233 & -11.0318 & 1.79 \\
\hline 43 & 36 & 0.0503 & 0.05038 & 0.16 & -0.0131 & -0.01361 & 3.89 & -11.407 & -11.6896 & 2.48 \\
\hline 44 & 28 & 0.0530 & 0.05321 & 0.40 & -0.0132 & -0.01368 & 3.64 & -13.324 & -13.2299 & 0.71 \\
\hline 45 & 8 & 0.0557 & 0.05539 & 0.56 & -0.0138 & -0.01401 & 1.52 & -15.025 & -14.8574 & 1.12 \\
\hline 46 & 39 & 0.0599 & 0.05924 & 1.10 & -0.0154 & -0.01572 & 2.08 & -16.978 & -16.8970 & 0.48 \\
\hline 47 & 49 & 0.0621 & 0.06288 & 1.26 & -0.0161 & -0.01642 & 1.99 & -17.335 & -17.2313 & 0.60 \\
\hline 48 & 42 & 0.0681 & 0.06820 & 0.15 & -0.0167 & -0.01718 & 2.87 & -18.000 & -18.1929 & 1.07 \\
\hline 49 & 14 & 0.0729 & 0.07265 & 0.34 & -0.0183 & -0.01842 & 0.66 & -18.457 & -18.2228 & 1.27 \\
\hline 50 & 48 & 0.0757 & 0.07670 & 1.32 & -0.0189 & -0.01921 & 1.64 & -19.002 & -19.3053 & 1.60 \\
\hline 51 & 3 & 0.0784 & 0.07849 & 0.11 & -0.0196 & -0.02000 & 2.04 & -19.067 & -19.0213 & 0.24 \\
\hline 52 & 38 & 0.0812 & 0.08231 & 1.37 & -0.0202 & -0.02077 & 2.82 & -20.034 & -20.2361 & 1.01 \\
\hline 53 & 25 & 0.0841 & 0.08421 & 0.13 & -0.0217 & -0.02217 & 2.17 & -21.021 & -21.1247 & 0.49 \\
\hline 54 & 12 & 0.0859 & 0.08581 & 0.10 & -0.0224 & -0.02278 & 1.70 & -22.321 & -22.4367 & 0.52 \\
\hline \multicolumn{4}{|r|}{$\operatorname{Min} P E(\%)$} & 0.1 & \multicolumn{2}{|r|}{ Min $P E(\%)$} & 0.06 & \multicolumn{2}{|r|}{ Min $P E(\%)$} & 0.24 \\
\hline \multicolumn{4}{|c|}{$\operatorname{Max} P E(\%)$} & 3.13 & \multicolumn{2}{|c|}{$\operatorname{Max} P E(\%)$} & 3.92 & \multicolumn{2}{|r|}{$\operatorname{Max} P E(\%)$} & 4.71 \\
\hline \multicolumn{4}{|c|}{ Mean $P E(\%)$} & 1.29 & \multicolumn{2}{|c|}{ Mean $P E(\%)$} & 2.13 & \multicolumn{2}{|c|}{ Mean $P E(\%)$} & 2.32 \\
\hline
\end{tabular}


Vukelic, Kanovic, Sokac, Santosi, Budak, Tadic: Modelling of Micro-Turning Process Based ...

Table III: Experimental data for confirmation of the artificial neural network model.

\begin{tabular}{|c|c|c|c|c|c|c|c|c|c|c|c|c|c|}
\hline No. & $\begin{array}{c}F \\
(\mathrm{~N}) \\
\end{array}$ & $\begin{array}{c}n \\
\text { (rev/min) }\end{array}$ & $\begin{array}{c}t \\
(\mathrm{~s})\end{array}$ & $\begin{array}{c}D_{1} \\
(\mathrm{~mm})\end{array}$ & $\begin{array}{c}D_{2} \\
(\mathrm{~mm})\end{array}$ & $\begin{array}{c}\Delta D \\
(\mathrm{~mm})\end{array}$ & $\begin{array}{c}C_{1} \\
(\mathrm{~mm})\end{array}$ & $\begin{array}{c}C_{2} \\
(\mathrm{~mm})\end{array}$ & $\begin{array}{c}\Delta C \\
(\mathrm{~mm})\end{array}$ & $\begin{array}{l}R a_{1} \\
(\mu \mathrm{m})\end{array}$ & $\begin{array}{l}R a_{2} \\
(\mu \mathrm{m})\end{array}$ & $\begin{array}{c}\Delta R \\
(\mu \mathrm{m})\end{array}$ & $\begin{array}{c}a_{p} \\
(\mu \mathrm{m})\end{array}$ \\
\hline 1 & 1.5 & 75 & 12.5 & 35.0931 & 35.0904 & 0.0027 & 0.0371 & 0.0226 & 0.0145 & 0.813 & 0.292 & 0.521 & 1.35 \\
\hline 2 & 1.5 & 125 & 17.5 & 35.0847 & 35.0806 & 0.0041 & 0.0365 & 0.0222 & 0.0143 & 0.812 & 0.375 & 0.437 & 2.05 \\
\hline 3 & 2.5 & 75 & 12.5 & 35.0922 & 35.0866 & 0.0056 & 0.0379 & 0.0276 & 0.0103 & 0.807 & 0.387 & 0.42 & 2.8 \\
\hline 4 & 2.5 & 125 & 17.5 & 35.0909 & 35.0837 & 0.0072 & 0.0363 & 0.0299 & 0.0064 & 0.806 & 0.434 & 0.372 & 3.6 \\
\hline 5 & 3.5 & 75 & 12.5 & 35.0809 & 35.0711 & 0.0098 & 0.0362 & 0.0337 & 0.0025 & 0.803 & 0.889 & -0.086 & 4.9 \\
\hline 6 & 3.5 & 125 & 17.5 & 35.1022 & 35.0897 & 0.0125 & 0.0364 & 0.0375 & -0.0011 & 0.802 & 1.079 & -0.277 & 6.25 \\
\hline 7 & 4.5 & 75 & 12.5 & 35.0978 & 35.0705 & 0.0273 & 0.0374 & 0.0453 & -0.0079 & 0.803 & 5.624 & -4.821 & 13.65 \\
\hline 8 & 4.5 & 125 & 17.5 & 35.0901 & 35.0554 & 0.0347 & 0.0364 & 0.0454 & -0.0090 & 0.803 & 8.538 & -7.735 & 17.35 \\
\hline 9 & 5.5 & 75 & 12.5 & 35.1045 & 35.0482 & 0.0563 & 0.0378 & 0.0524 & -0.0146 & 0.804 & 12.376 & -11.572 & 28.15 \\
\hline 10 & 5.5 & 125 & 17.5 & 35.1035 & 35.0385 & 0.0650 & 0.0374 & 0.0548 & -0.0174 & 0.806 & 16.635 & -15.829 & 32.5 \\
\hline \multicolumn{4}{|r|}{ Mean } & 35.0940 & 35.0715 & 0.0225 & 0.0369 & 0.0371 & -0.0002 & 0.806 & 4.663 & -3.857 & 11.26 \\
\hline \multicolumn{4}{|c|}{ Minimum } & 35.0809 & 35.0385 & 0.0027 & 0.0362 & 0.0222 & -0.0174 & 0.802 & 0.292 & -15.829 & 1.35 \\
\hline \multicolumn{4}{|c|}{ Maximum } & 35.1045 & 35.0904 & 0.0650 & 0.0379 & 0.0548 & 0.0145 & 0.813 & 16.635 & 0.521 & 32.50 \\
\hline \multicolumn{4}{|c|}{ Standard Deviation } & 0.0080 & 0.0184 & 0.0227 & 0.0007 & 0.0119 & 0.0117 & 0.004 & 5.958 & 5.959 & 11.34 \\
\hline
\end{tabular}

Table IV: Confirmation experiments errors.

\begin{tabular}{|c|c|c|c|c|c|c|c|c|c|}
\hline \multirow[b]{2}{*}{ No. } & \multicolumn{3}{|c|}{ Diameter $\Delta D$} & \multicolumn{3}{|c|}{ Circularity $\Delta C$} & \multicolumn{3}{|c|}{ Roughness $\Delta R$} \\
\hline & $\begin{array}{l}\text { Measured } \\
(\mathrm{mm})\end{array}$ & $\begin{array}{l}\text { Predicted } \\
(\mathrm{mm})\end{array}$ & $\begin{array}{l}P E \\
(\%) \\
\end{array}$ & $\begin{array}{c}\text { Measured } \\
(\mathrm{mm})\end{array}$ & $\begin{array}{l}\text { Predicted } \\
\quad(\mathrm{mm})\end{array}$ & $\begin{array}{l}P E \\
(\%)\end{array}$ & $\begin{array}{c}\text { Measured } \\
(\mu \mathrm{m})\end{array}$ & \begin{tabular}{|c}
$\begin{array}{c}\text { Predicted } \\
(\mathrm{mm})\end{array}$ \\
\end{tabular} & $\begin{array}{l}P E \\
(\%)\end{array}$ \\
\hline 1 & 0.0027 & 0.00272 & 0.81 & 0.0145 & 0.01432 & 1.23 & 0.5210 & 0.5104 & 2.03 \\
\hline 2 & 0.0041 & 0.00406 & 0.98 & 0.0143 & 0.01402 & 1.96 & 0.4370 & 0.4458 & 2.01 \\
\hline 3 & 0.0056 & 0.00567 & 1.27 & 0.0103 & 0.01040 & 0.97 & 0.4200 & 0.4117 & 1.98 \\
\hline 4 & 0.0072 & 0.00728 & 1.11 & 0.0064 & 0.00631 & 1.41 & 0.3720 & 0.3785 & 1.75 \\
\hline 5 & 0.0098 & 0.00973 & 0.71 & 0.0025 & 0.00256 & 2.28 & -0.0860 & -0.0869 & 1.05 \\
\hline 6 & 0.0125 & 0.01265 & 1.21 & -0.0011 & -0.00112 & 1.82 & -0.2770 & -0.2851 & 2.92 \\
\hline 7 & 0.0273 & 0.02851 & 4.43 & -0.0079 & -0.00833 & 5.44 & -4.8210 & -5.1069 & 5.93 \\
\hline 8 & 0.0347 & 0.03289 & 5.21 & -0.0090 & -0.00971 & 7.89 & -7.7350 & -7.0907 & 8.33 \\
\hline 9 & 0.0563 & 0.05557 & 1.30 & -0.0146 & -0.01443 & 1.16 & -11.5720 & -11.8127 & 2.08 \\
\hline 10 & 0.0650 & 0.06405 & 1.46 & -0.0174 & -0.01771 & 1.78 & -15.8290 & -15.6267 & 1.28 \\
\hline \multirow{2}{*}{\multicolumn{3}{|c|}{$\frac{\operatorname{Min} P E(\%)}{\operatorname{Max} P E(\%)}$}} & 0.71 & \multirow{2}{*}{\multicolumn{2}{|c|}{$\frac{\operatorname{Min} P E(\%)}{\operatorname{Max} P E(\%)}$}} & 0.97 & \multicolumn{2}{|r|}{ Min $P E(\%)$} & 1.05 \\
\hline & & & 5.21 & & & 7.89 & & $\operatorname{Max} P E(\%)$ & 8.33 \\
\hline \multicolumn{3}{|c|}{ Mean $P E(\%)$} & 1.85 & \multicolumn{2}{|c|}{ Mean $P E(\%)$} & 2.59 & \multicolumn{2}{|c|}{ Mean $P E(\%)$} & 2.94 \\
\hline
\end{tabular}

\section{DISCUSSION}

By analysing the results, it can be noticed that depending on the machining parameters, the resulting change in diameter is $0.0011-0.0859 \mathrm{~mm}$, and the achieved cutting depth ranges from $0.55-42.95 \mu \mathrm{m}$. These results indicate that extremely small cutting depths can be achieved with the proposed machining method. The lowest cutting depth is obtained during machining with the lowest force, in the shortest machining time and with the lowest number of revolutions. The obtained circularity after machining is in the range of $0.0204-0.0605 \mathrm{~mm}$, and the maximum improvement of circularity after machining, in relation to the initial circularity, is $0.0172 \mathrm{~mm}$. The achieved circularity after machining suggests obtaining extremely good shape tolerance. The achieved arithmetic mean roughness after machining is $0.0196-23.124 \mu \mathrm{m}$. These results indicate the possibility of obtaining a high quality of the treated surface (ISO grade numbers). Roughness control in a wide range also provides control of cutting depth and circularity in a very wide range, with respect to their direct dependence. The analysis of the results shows a direct dependence of the achieved cutting depth and circularity on the roughness of the machined surface. From Figs. 5 and 6 it can be seen that low cutting forces cause a decrease in roughness. The reduction in roughness is due to the small cutting depths. Smaller penetrating forces of the tool into the workpiece cause a change in diameter of several $\mu \mathrm{m}$. This leads to the conclusion that the contact between the cutting tool and the workpiece in these conditions is realized only through the tips of the unevenness, ie. over the tips of the bulges on the 
roughness profile. This means that the change in diameter is a consequence of the reduction in the height of the peaks of the unevenness. This phenomenon is illustrated by one example in Fig. 7.

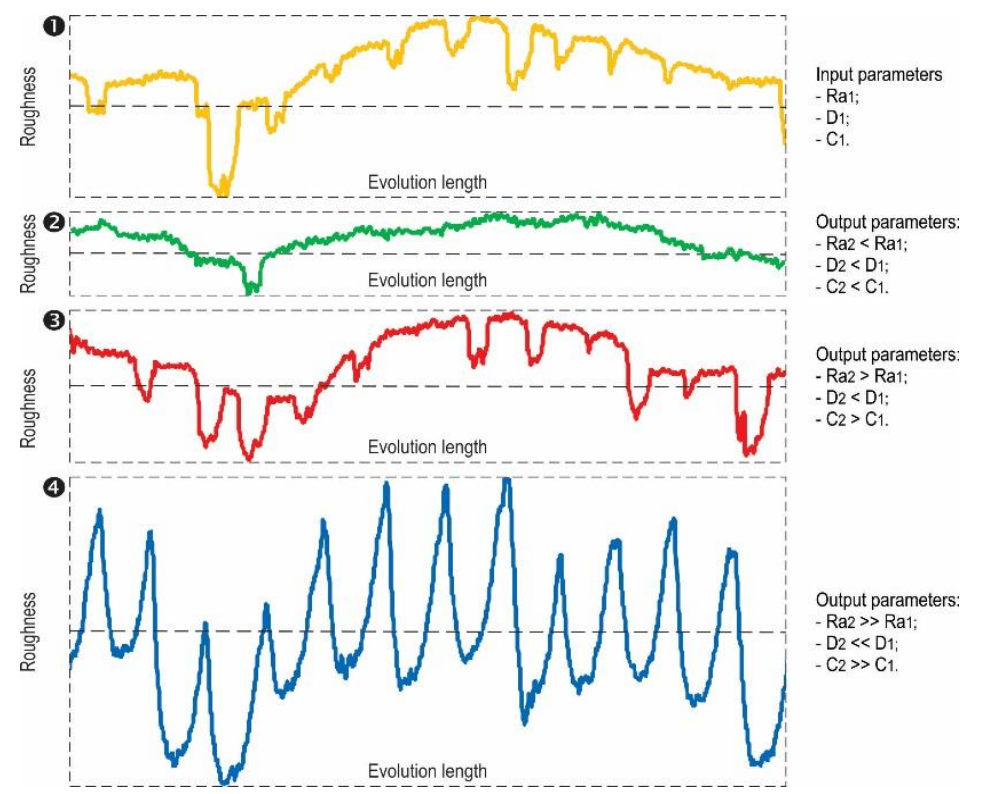

1. before machining,

2. during machining - improvement of circularity and roughness,

3. during machining - deterioration of circularity and roughness,

4. during machining - significant deterioration of circularity and roughness

Figure 7: Characteristic roughness profiles of the machined surface.

Furthermore, at the same machining parameters, identical phenomena occur when the roughness and circularity change. The correlation between these two parameters is obvious. The deviation of the circularity decreases with decreasing cutting force. Small forces make contact with the workpiece on the tips of the unevenness and machining is performed at the micro level, which ensures the improvement of roughness. When the cutting force exceeds a critical value for certain machining conditions, micro-cutting turns into a macro-cutting. At a force of $5 \mathrm{~N}$ there is a sharp increase in cutting depth, deterioration of roughness and deterioration of cylindricity. By the action of greater force, the cutting edge penetrates the workpiece below the root of the unevenness, which leads to a deeper cutting depth. Increasing the cutting depth causes an increase in roughness and deterioration of the circularity. It can be concluded that higher cutting forces lead to greater cutting depth and to intermittent cutting in certain zones on the circular path. Intermittent cutting directly affects the increase of surface roughness and thus leads to a larger deviation of the circularity.

Based on the obtained $P E$ and $M P E$, it can be concluded that for all three output machining characteristics (diameter, circularity and roughness) this value does not exceed $10 \%$. The smallest deviation occurs with a change in diameter and it is $5.21 \%$ and the largest with a change in roughness and it is $8.33 \%$. Inspection of the percentage errors reveals that the largest $P E$ occurs in the vicinity of a critical force of $5 \mathrm{~N}$. The term critical force means a force that causes a significant increase in cutting depth, significant deterioration of circularity and significant deterioration of roughness. The percentage errors obtained during machining with forces of $4.5 \mathrm{~N}$ indicate that the neural network had problems when dealing with these two outliers. This is exactly the zone in which the changes in the diameter, circularity and roughness occur.

\section{CONCLUSION}

To reduce dimensional error, shape error and the surface roughness of the workpiece, a methodology has been developed for achieving the cutting process with a constant cutting force using conventional cutting tools. 
The results of experimental research indicate that with the increase of cutting force, number of revolutions and machining time, the change of external diameter increases, i.e., a greater cutting depth is achieved. The bigger number of revolutions results in a larger circular trajectory (length) of turning and a longer machining time causes a longer contact between the workpiece and the cutting tool. The tested method, at small cutting forces, small number of revolutions and short machining time, provides the possibility of extremely fine regulation of the diameter of workpieces, so it can be used to achieve high dimensional accuracy and reduce circularity deviation. Considering that dimensional accuracy and cylindricity are obtained at the expense of reducing roughness, the proposed method also provides surfaces with extremely low roughness. Since machining is based on a constant cutting force, the forces should be selected so that they are always less than the critical value.

Also, the prediction errors of the machining output parameters obtained using ANN are within the limits of acceptability. Mean percentage errors indicate deviations that can be considered acceptable for the practical application of the neural network in the industry.

Future research will be focused on the investigation of the process of micro-cutting workpieces from different materials, with different cutting tools and with different machining parameters. Furthermore, it is planned to reconstruct the module for setting the constant cutting force to enable other turning operations.

\section{ACKNOWLEDGEMENT}

The results presented in this paper are obtained in the framework of the project entitled "Innovative scientific and artistic research from the FTS (activity) domain" funded by the Ministry of Education, Science and Technological Development of Republic of Serbia.

\section{REFERENCES}

[1] Jo, C. H.; Kim, B. H.; Chu, C. N. (2009). Micro electrochemical machining for complex internal micro features, CIRP Annals, Vol. 58, No. 1, 181-184, doi:10.1016/j.cirp.2009.03.072

[2] Pellegrini, G.; Ravasio, C. (2019). Evaluation of the sustainability of the micro-electrical discharge milling process, Advances in Production Engineering \& Management, Vol. 14, No. 3, 343-354, doi:10.14743/apem2019.3.332

[3] Sloyan, K.; Melkonyan, H.; Dahlem, M. S. (2020). Focused ion beam milling for prototyping 2D and 3D photonic structures, The International Journal of Advanced Manufacturing Technology, Vol. 107, No. 11, 4469-4480, doi:10.1007/s00170-020-05327-5

[4] Yin, C. P.; Wu, Z. P.; Dong, Y. W.; You, Y. C.; Liao, T. (2019). Femtosecond laser helical drilling of nickel-base single-crystal super-alloy: Effect of machining parameters on geometrical characteristics of micro-holes, Advances in Production Engineering \& Management, Vol. 14, No. 4, 407-420, doi:10.14743/apem2019.4.337

[5] Boswell, B.; Islam, M. N.; Davies, I. J. (2017). A review of micro-mechanical cutting, The International Journal of Advanced Manufacturing Technology, Vol. 94, No. 1, 789-806, doi:10.1007/s00170-017-0912-y

[6] Sterpin Valic, G.; Cukor, G.; Jurkovic, Z.; Brezocnik, M. (2019). Multi-criteria optimization of turning of martensitic stainless steel for sustainability, International Journal of Simulation Modelling, Vol. 18, No. 4, 632-642, doi:10.2507/IJSIMM18(4)495

[7] Ficko, M.; Begic-Hajdarevic, D.; Hadziabdic, V.; Klancnik, S. (2020). Multi-response optimisation of turning process parameters with GRA and TOPSIS methods, International Journal of Simulation Modelling, Vol. 19, No. 4, 547-558, doi:10.2507/IJSIMM19-4-524

[8] Mijuskovic, G.; Krajnik, P.; Kopac, J. (2013). Improvement of positional accuracy of precision micro milling center using pitch error compensation, Tehnicki vjesnik - Technical Gazette, Vol. 20, No. 4, 629-634 
[9] Ramesh, R.; Mannan, M. A.; Poo, A. N. (2000). Error compensation in machine tools - a review: Part I: geometric, cutting-force induced and fixture-dependent errors, International Journal of Machine Tools and Manufacture, Vol. 40, No. 9, 1235-1256, doi:10.1016/s0890-6955(00)00009-2

[10] Sarić, T.; Vukelić, Đ.; Šmunović, K.; Svalina, I.; Tadić, B.; Prica, M.; Šimunović, G. (2020). Modelling and prediction of surface roughness in CNC turning process using neural networks, Tehnicki vjesnik - Technical Gazette, Vol. 27, No. 6, 1923-1930, doi:10.17559/TV20200818114207

[11] Zmarzły, P. (2020). Technological heredity of the turning process, Tehnicki vjesnik - Technical Gazette, Vol. 27, No. 4, 1194-1203, doi:10.17559/TV-20190425150325

[12] Tzotzis, A.; García-Hernández, C.; Huertas-Talón, J.-L.; Kyratsis, P. (2020). 3D FE modelling of machining forces during AISI 4140 hard turning, Strojniski vestnik - Journal of Mechanical Engineering, Vol. 66, No. 7-8, 467-478, doi:10.5545/sv-jme.2020.6784

[13] Piotrowska, I.; Brandt, C.; Karimi, H. R.; Maass, P. (2009). Mathematical model of micro turning process, The International Journal of Advanced Manufacturing Technology, Vol. 45, No. 1, 33-40, doi:10.1007/s00170-009-1932-z

[14] Gaitonde, V. N.; Karnik, S. R.; Silva, L. R.; Abrao, A. M.; Davim, J. P. (2009). Machinability study in microturning of PA66 GF30 polyamide with a PCD tool, Materials and Manufacturing Processes, Vol. 24, No. 12, 1290-1296, doi:10.1080/10426910903130115

[15] De Oliveira, J. A.; Ribeiro Filho, S. L. M.; Lauro, C. H.; Brandao, L. C. (2017). Analysis of the micro turning process in the Ti-6Al-4V titanium alloy, The International Journal of Advanced Manufacturing Technology, Vol. 92, No. 9, 4009-4016, doi:10.1007/s00170-017-0449-0

[16] Son, S. M.; Lim, H. S.; Ahn, J. H. (2006). The effect of vibration cutting on minimum cutting thickness, International Journal of Machine Tools and Manufacture, Vol. 46, No. 15, 2066-2072, doi:10.1016/j.ijmachtools.2005.12.011

[17] Bodziak, S.; de Souza, A. F.; Rodrigues, A. R.; Diniz, A. E.; Coelho, R. T. (2013). Surface integrity of moulds for microcomponents manufactured by micromilling and electro-discharge machining, Journal of the Brazilian Society of Mechanical Sciences and Engineering, Vol. 36, 623-635, doi:10.1007/s40430-013-0108-9

[18] Son, S. M.; Lim, H. S.; Ahn, J. H. (2005). Effects of the friction coefficient on the minimum cutting thickness in micro cutting, International Journal of Machine Tools and Manufacture, Vol. 45, No. 4-5, 529-535, doi:10.1016/j.ijmachtools.2004.09.001

[19] Geng, Y.; Wang, J.; Zhang, J.; Cai, J.; Yan, Y. (2019). A probe-based force-controlled nanoindentation system using an axisymmetric four-beam spring, Precision Engineering, Vol. 56, 530-536, doi:10.1016/j.precisioneng.2019.02.011

[20] Chen, Y.-L.; Cai, Y.; Tohyama, K.; Shimizu, Y.; Ito, S.; Gao, W. (2017). Auto-tracking single point diamond cutting on non-planar brittle material substrates by a high-rigidity force controlled fast tool servo, Precision Engineering, Vol. 49, 253-261, doi:10.1016/j.precisioneng.2017.02.014

[21] Lin, J.; Lian, R.-J. (2011). Hybrid self-organizing fuzzy and radial basis-function neural-network controller for constant cutting force in turning, The International Journal of Advanced Manufacturing Technology, Vol. 53, No. 9, 921-933, doi:10.1007/s00170-010-2894-x

[22] Tarng, Y. S.; Wang, Y. S. (1994). A new adaptive controller for constant turning force, The International Journal of Advanced Manufacturing Technology, Vol. 9, No. 4, 211-216, doi:10.1007/BF01751118

[23] Fuh, K.-H.; Chen, C.-T. (1997). Constant turning force operation with a fixed metal removal rate via a prior fuzzy controller system, Journal of Materials Processing Technology, Vol. 70, No. 13, 116-121, doi:10.1016/S0924-0136(97)00047-2

[24] Hsieh, C.-H.; Chou, J.-H.; Wu, Y.-J. (2002). Optimal predicted fuzzy controller of a constant turning force system with fixed metal removal rate, Journal of Materials Processing Technology, Vol. 123, No. 1, 22-30, doi:10.1016/S0924-0136(02)00008-0

[25] Lian, R.-J.; Lin, B.-F.; Huang, J.-H. (2005). A grey prediction fuzzy controller for constant cutting force in turning, International Journal of Machine Tools and Manufacture, Vol. 45, No. 9, 10471056, doi:10.1016/j.ijmachtools.2004.11.023

[26] Pitstra, W. C.; Pieper, J. K. (2000). Controller designs for constant cutting force turning machine control, ISA Transactions, Vol. 39, No. 2, 191-203, doi:10.1016/S0019-0578(00)00008-2 